\title{
Preventive Group Training Improves Children's Outcomes after Divorce: A Dutch Quasi-experimental Study
}

\author{
Mariska Klein Velderman $\mathbb{D}^{1} \cdot$ Paula van Dommelen ${ }^{1} \cdot$ Fieke D. Pannebakker $^{1} \cdot$ Sijmen A. Reijneveld ${ }^{1,2}$
}

Accepted: 19 December 2021 / Published online: 13 January 2022

(c) The Author(s) 2022

\begin{abstract}
Worldwide, many children experience parental separation and divorce. This has a significant impact on their well-being, and emotional and behavioral functioning, and calls for prevention. To assess the effects of the Children of Divorce Intervention Program in the Netherlands (CODIP-NL) on 6- to 8-year-olds, we performed a quasi-experimental effect study. The study compared children receiving CODIP-NL (intervention: I, $n=104$ ), children not receiving CODIP-NL but having divorced parents (divorced control: DC, $n=37$ ), and children belonging to non-divorced families (non-divorced control: NDC, $n=138$ ). Outcomes pertained to children's positive functioning, emotional and behavioral problems, and well-being. We assessed pre- to post-test differences in change in mother-reported outcomes between the intervention and control groups, and pre- to post-test differences in group leader reports. The intervention led to increases in mother-reported positive functioning $(d=0.97$ I vs. DC; $d=1.04$ I vs. NDC), and well-being ( $d=1.00$ I vs. DC; $d=0.84$ I vs. NDC). Mother-reported child emotional and behavioral problems decreased after participation (total difficulties, $d=0.73$ I vs. DC; $d=0.49$ I vs. NDC). Group leader-reported pre- to post-test differences $(p \leq 0.001)$ pointed in the same directions. Findings support further implementation of CODIP to support children's positive functioning and well-being, and to decrease emotional and behavioral problems after their parents' divorce.
\end{abstract}

Keywords Parental divorce $\cdot$ Parental separation $\cdot$ Intervention $\cdot$ Emotional and behavioral problems $\cdot$ Well-being

\section{Highlights}

- The high prevalence of parental divorce and its high risks for child well-being and functioning urgently call for prevention of problems for these children and support as they adapt to the divorce.

- Effective intervention programs are relatively rare. One of the few is the Children of Divorce Intervention Program (CODIP), aimed at preventing divorce-related problems in primary school children. Evidence is limited regarding its effects outside the US.

- This study in the Netherlands showed that CODIP-NL effectively promotes the emotional well-being and positive functioning of young children involved in parental divorce, and reduces their emotional and behavioral problems.

- These findings support wider implementation of CODIP to effectively strengthen children's adaptation to parental divorce.

Supplementary information The online version contains supplementary material available at https://doi.org/10.1007/s10826021-02220-x.

Mariska Klein Velderman

Mariska.kleinvelderman@tno.nl

1 Department of Child Health, Healthy Living Unit, Netherlands Organization for Applied Scientific Research, TNO, P.

O. Box 3005, 2301 DA Leiden, the Netherlands

2 Department of Health Sciences, University Medical Center Groningen, University of Groningen, P.O. Box 72, 9700 AB Groningen, the Netherlands
Each year in the European Union (EU-27), about 0.8 million marriages end in divorce; this means a crude divorce rate of 2 for every 1000 persons (Eurostat, 2020). By comparison, 1.9 million marriages took place in 2018, which equals a crude marriage rate of 4.4 for every 1000 persons (Eurostat, 2020). In the United States, crude divorce and marriage rates in 2018 equaled 2.9 and 6.5, respectively (CDC, 2020). These numbers do not include the separation of registered and cohabiting partnerships; the latter are also numerous, but exact numbers are not available (Boertien, 2020). In many of these divorce and 
separation cases, children are involved. In England and Wales, for example, approximately half of the couples divorcing between 2009 and 2013 had at least one child under the age of 16 (Office for National Statistics, 2015). In the Netherlands, $56 \%$ of divorced couples had children, meaning that more than one of every five children in the Netherlands experience parental separation during their lifetime (Research and Documentation Centre - WODC, 2019). Each year in the Netherlands, 86,000 children experience their parents' divorce or separation (Lemmers et al., 2019). In these cases of breaking up of partnerships or union dissolutions between parents, parental "divorces" and "separations" of registered and cohabiting partnerships are to large extent analog, in terms of procedures and trajectories.

Divorce of their parents (from here on "divorce" refers to both separation and divorce) has been found to be an important risk factor for less optimal development of children. Meta-analyses by Amato and colleagues (Amato, 2001; Amato \& James, 2010) as well as more recent studies (e.g., Benardi \& Radl, 2014; Carr \& Wolchik, 2015; Dissing et al., 2017; Van Dijk et al., 2020; Weaver \& Schofield, 2015) show that, on average, children of divorce achieve less well in school, show more behavioral problems, score lower on psychological and emotional well-being, have lower self-esteem, and encounter more problems in social relationships than children from non-divorced families. In later life, having experienced parental divorce in childhood is associated with a higher prevalence of problems, such as sick leave, psychological problems, depression, substance use, teenage parenthood, problematic relationships, and dissolution of one's own marriage (e.g., Amato \& James, 2010; Bohman et al., 2017).

Preventing problems for children of divorce and helping them adapt to the divorce are therefore major priorities, but effective intervention programs are still rare. One of the few is the Children of Divorce Intervention Program (CODIP), developed in the United States (e.g., Pedro-Carroll, 2005) and aimed at preventing divorce-related problems in young primary school children. However, evidence regarding its effects outside the US is still limited. This program was therefore culturally adapted, paving the way to CODIP-NL. Its feasibility has already been assessed in the Dutch setting, and has proven to be good (Klein Velderman et al., 2018). The training was found to be very much appreciated by group leaders and participating children $(n=43)$ and their parents. Children felt secure in the small group and expressed to have learned something. This was confirmed by their mothers, who had seen positive changes in their children since the start of CODIP-NL (Klein Velderman et al., 2018). CODIP-NL received scientific validation (denoted as theoretically well underpinned and good indications for effectiveness) in the Dutch National Registry of
Effective Youth Interventions (Klein Velderman \& Pannebakker, 2019).

The aim of the current paper was to assess the effectiveness of CODIP-NL for 6- to 8-year-old children in the Dutch setting. We tested our hypothesis that CODIP-NL would: (1) increase participating children's positive functioning, (2) improve their emotional and behavioral functioning, and (3) enhance their well-being.

\section{Method}

We performed a three-arm, non-randomized, quasiexperimental study, registered as NL6606 in the Dutch trial register (https://www.trialregister.nl/trial/6606). Three groups were compared: a group of children receiving CODIP-NL (intervention: I); a group of children not receiving CODIP-NL, who have divorced parents (divorced control: DC); and a group of children whose parents were not divorced (non-divorced control: NDC). This enabled us to detect enhanced positive functioning, emotional and behavioral functioning and well-being, as a result of the intervention and to separate this for instance from "natural recovery" after divorce (I vs. DC), and from maturation or testing effects (I vs. NDC and DC). We report this study following the CONSORT 2010 guidelines (see CONSORT Checklist in Appendix). The Leiden University Medical Centre Institutional Review Board approved the pilot study of CODIP-NL (P09.083), and extended this approval to the main study as reported here.

A sample size of 52 children per group was needed to detect, with a two-sided 5\% significance level and a power of $80 \%$, the smallest Cohen's $d$ effect size found for the primary outcomes in the pilot study (Klein Velderman et al., 2018). These effect sizes were 0.56 for mother-reported child positive functioning as assessed using the Parent Evaluation Form (PEF, by Pedro-Carroll \& Cowen, 1985, Dutch translation) and 0.76 for mother-reported child emotional and behavioral problems as measured using the Strengths and Difficulties Questionnaire for ages 4-16 (SDQ, by Goodman, 1997, Parent Form, total difficulties). Given an anticipated dropout rate of $10 \%$, we aimed at the inclusion of 58 children per study group. We anticipated needing a 24-month inclusion period to recruit this number of children.

\section{Sample}

We used the following inclusion criteria: (a) parent separation or divorce, (b) children not currently in therapy or receiving other mental health services (excluding routine preventive psychosocial care), and (c) permission by both parents who have custody rights. Our criteria were similar 
to those used in the U.S. studies (Alpert-Gillis, PedroCarroll \& Cowen, 1989). One comparison group involved children not experiencing parental divorce but who further fulfilled criteria $\mathrm{b}$ and $\mathrm{c}$.

Children in the intervention group (I, $n=104)$ were included from March 2015 to March 2017, via current communication between social work, preventive child healthcare, or youth social care professionals and their clients or partners in the field (by means of website social media, brochures, personal contact). To include children in the control groups (children of divorced controls, DC, and of non-divorced controls, NDC) we followed two routes. First, via several channels, from March 2015 to March 2017, we invited divorced parents of children meeting the further above criteria to take part in an online survey: (a) professionals in the field informed the schools they worked with and used participation in the study as a waiting list option for parents of children included in their CODIP-NL groups; (b) we placed open invitations on social media; and (c) we approached schools, mediators, and family lawyers directly by phone, asking them to find parents willing to participate. This yielded 29 children for the DC group $(n=29)$. Second, from November 2016 to March 2017, we invited parents of children in the third and fourth grades (approximate age 6-8 years) of twelve Dutch primary schools to participate in an online survey regarding child development, child well-being and impactful life events. If parents indicated having divorced, they received additional questions and their children were included in the DC group. This yielded 8 DC children (total DC group $n=37$ ). Children whose parents had not divorced became part of the NDC group $(n=138)$.

\section{Intervention}

Children in the intervention group received CODIP-NL (in Dutch denoted as "Dappere Dino's", i.e., "Courageous Dinosaurs"), consisting of 12 weekly 45-min sessions. CODIP-NL aims at preventing divorce-related problems in children by: (a) creating a supportive group environment, (b) facilitating identification and appropriate expression of feelings, (c) promoting accurate understanding of divorcerelated concepts and clarifying divorce-related misconceptions, (d) enhancing children's problem-solving skills, and (e) enhancing children's perceptions of self and family. The training has been developed and evaluated in the US setting (Alpert-Gillis et al., 1989; Pedro-Carroll \& Cowen, 1985; Pedro-Carroll et al., 1999), and next adapted to the Dutch setting (Klein Velderman et al., 2018). It is based on theories of play therapy, developmental psychology, stress and coping, resilience promotion, and research on risk and protective factors (Alpert-Gillis et al., 1989; Pedro-Carroll \& Klein Velderman, 2015). Dinosaur hand puppet Rex plays a central role in CODIP-NL group sessions. Group leaders use Rex to give words to divorce-related thoughts and feelings. Rex is the same age as the participants, and shares with them his experiences about the divorce of his own parents. He is also an important role model in practicing problem-solving skills. In addition to puppet play, group leaders use many creative materials and games (e.g., reading books, board games, posters, picture cards, role play).

The intervention was offered to children at school or at the local health center. In accordance with the structured program manual, group leaders playfully focused on identification and expression of feelings, teaching participating children to deal with misconceptions and attitudes towards divorce and family, and strengthening their problem-solving skills. The CODIP-NL intervention groups were each led by two experienced professionals (e.g., social workers with a college or university degree in applied sciences). These professionals received face-to-face training, as well as sessions of telephone supervision and group intervision, to conduct groups according to the CODIP-NL manual. Parents received three newsletters as well as weekly mailings, and were invited to the intake, outtake, and one parent session (see Klein Velderman et al., 2018; Pedro-Carroll \& Klein Velderman, 2015). The intervention fidelity was evaluated using structured logbooks, filled out per session by the group leaders, as we did in the preceding feasibility study previously (Klein Velderman et al., 2018). These logbooks showed that group leaders deviated from the method in only a very limited number of instances. In those specific instances, the group leaders still aimed at the same goal, but in a different way, with a different activity (e.g., a different introductory exercise). In none of the groups, group leaders omitted parts of the intervention.

\section{Care as Usual}

Children in the care as usual groups (DC and NDC) received routine psychosocial care if needed. In the Netherlands, such care is provided either by the general practitioner or by preventive child healthcare, both accessible without charge. If needed, children can further be referred to family and social care or to child mental healthcare, both accessible without charge, but only after referral by primary care.

\section{Procedure}

The intervention was evaluated based on reports from group leaders (intermediate users, in the I group only) and mothers (end users). Informants completed questionnaires to evaluate children's positive functioning, well-being, and emotional and behavioral problems. Mothers received a questionnaire before the start (pre) and after (post) the final 
(12th) intervention session, or after 3 months (control groups). Group leader ratings were collected after sessions 4 (pre) and 12 (post). This resembles the procedure used for the U.S. research (Alpert-Gillis et al., 1989) and the pilot evaluation of CODIP-NL by Klein Velderman et al. (2018). Prior to the start of the intervention (I group), written informed consent was obtained for each child from both (custodial) parents, regarding participation in the study and the intervention. Parents in the DC and NDC groups received written procedural and privacy information and consented to participate as part of the pre-test questionnaire.

\section{Measures}

\section{Primary and secondary outcomes}

Primary outcomes were the child's positive functioning and its emotional and behavioral problems. The child's wellbeing was included as a secondary outcome.

\section{Positive functioning}

Parent- and group leader-reported child positive functioning was measured. Parent-reported child positive functioning was assessed using the Parent Evaluation Form (PEF, by PedroCarroll \& Cowen, 1985; Dutch translation as used in Klein Velderman et al., 2018). The PEF contains 22 items on parents' views of children's feelings (e.g., "Feels responsible for family problems if they occur"), behavior (e.g., "Talks with me about how he/she feels"), and problem-solving skills (e.g., "Tries to solve own problems"). Items are rated on a 4-point Likert scale ( $1=$ very true, to $4=$ not true at all). High PEF sum scores indicate better child adjustment. The pre-test alpha in the current study was 0.91 .

Group leader-reported child positive functioning was based on the Group Leader Evaluation Form (GLEF; Alpert-Gillis et al., 1989; translation as previously used in Klein Velderman et al., 2018). This 23-item questionnaire measures children's strengths or competences (e.g., "Expresses feelings appropriately" and "Recognizes differences between problems he/she can and cannot solve"), as well as problems that children of divorce may experience (e.g., "Believes he/she can bring parents together"), aggregating into an overall adjustment score. Group leaders rate each item on a 4-point Likert scale, ranging from $1=$ very true, to $4=$ not true at all. High scores indicate better adjustment. Cronbach's alpha for overall adjustment at pretest was 0.86 .

\section{Emotional and behavioral problems}

Children's emotional and behavioral problems were measured using the Strengths and Difficulties Questionnaire
(Goodman, 1997) for ages 4-16 (Parent Form, SDQ-PF, for parents; and Teacher Form, SDQ-TF for group leaders). The SDQ is a brief behavioral screening questionnaire consisting of 25 items (e.g., "Considerate of other people's feelings"; "Restless, overactive, cannot stay still for long"; and "Generally liked by other children"). Items are scored on a 3 -point scale $(0=$ not true, $1=$ somewhat true, and $2=$ certainly true). The SDQ generates scores for difficulties in four domains: conduct problems, hyperactivity, emotional symptoms, peer problems, and one strength domain, i.e., prosocial behavior. All but the last are added together to generate a total difficulties score (TDS). Cronbach's alphas for TDS in the current study were (pre-test): 0.71 (mothers) and 0.55 (group leaders).

\section{Well-being}

Parents and group leaders were asked to indicate on a 1-10 scale how well the child was doing at that time (adapted continuous "Cantril ladder"; Cantril, 1965; as previously used in Spruijt \& Duindam, 2010) as a measure of child well-being.

\section{Demographic and divorce-related characteristics}

The following demographics were measured: child's sex and age, country of birth of the parents, and parental education. In the intervention and divorce control groups, we also measured a selection of divorce-related variables, namely: time since the divorce, child custody arrangements (no, single, joint), availability of temporary or definite parenting plan, child support and parent alimony agreements, frequency of child's contact with both parents (more or less than once a week), whether or not parents had a new partner, presence of stepbrothers or -sisters, and divorce of grandparents. We also measured interparental conflict after the divorce, using five items of the Children's Perception of Interparental Conflict Scale (CPIC; Grych et al., 1992). Mothers were asked how often they argued about money, parenting, and contact with the child, and how often they disagreed on something, or had serious conflicts. Answers were given on a 5-point scale, ranging from $1=$ never, to $5=$ all the time. The average of at least 4 out of 5 items (i.e., missing on max. 1 item) generates the conflict awareness measure. Cronbach's alpha in this study was (pretest): 0.88 .

\section{Analyses}

First, we made descriptive analyses of the demographic characteristics and divorce-related characteristics of the sample. Second, we assessed the effect of CODIP-NL by assessing differences in change between pre- and post-measurements of 

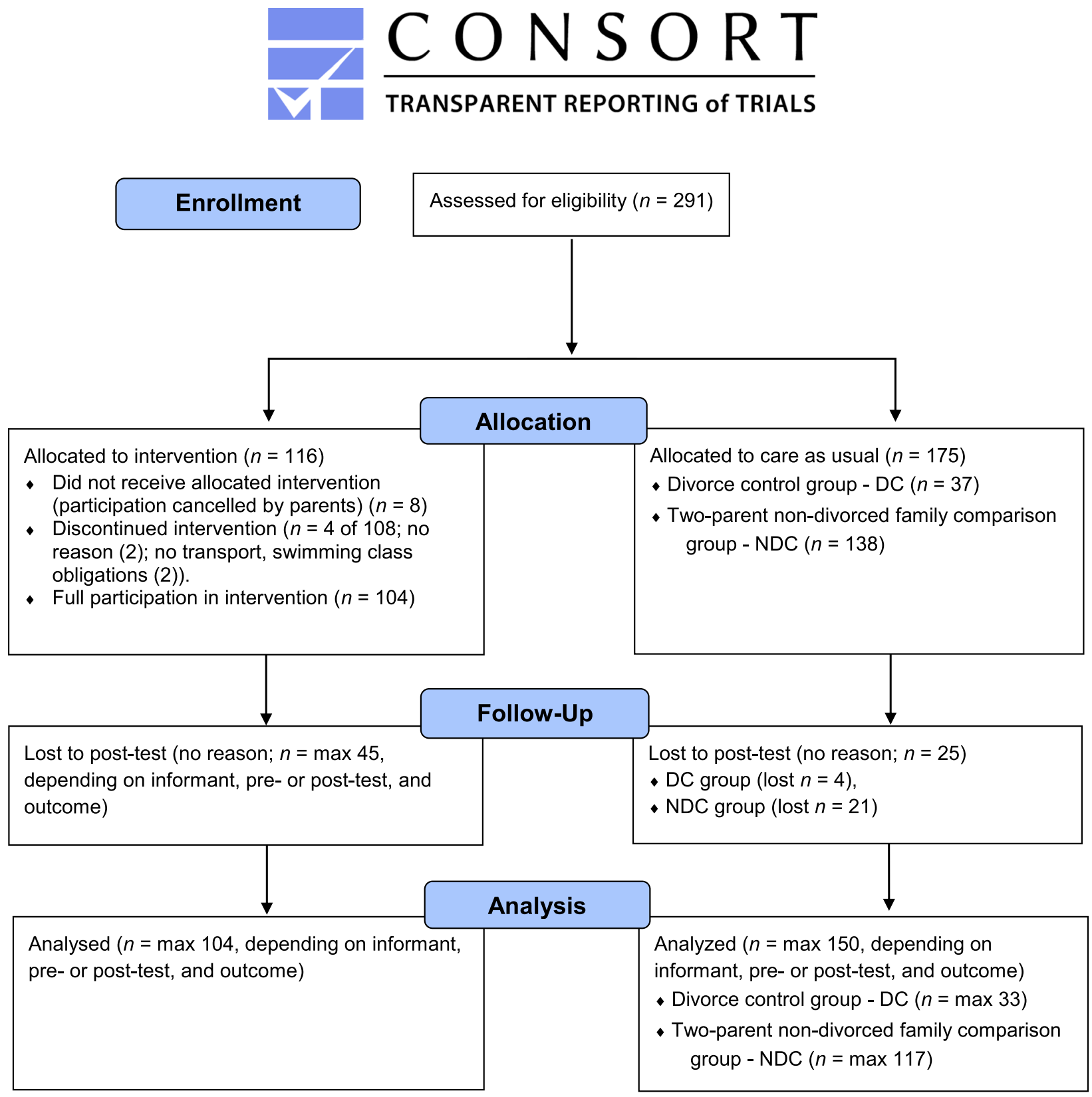

Fig. 1 Trial study subjects' flow diagram (CONSORT 2010)

the primary outcomes as reported by mothers for the I vs. the DC and NDC groups. We used one-way analyses of variance with contrast tests (I group as reference category), with and without adjustment for background characteristics, to evaluate group differences in changes from pre- to post-test on all primary and secondary outcomes: PEF positive functioning, SDQ-PF emotional and behavioral problems, and Cantril wellbeing. We used paired sample $t$-tests to evaluate pre- to posttest differences in GLEF positive functioning, SDQ-TF emotional and behavioral problems, and Cantril well-being as reported by group leaders (only available for the I group).
We applied an available case analysis approach (pairwise deletion), in order to maximize all data available by an analysis basis.

\section{Results}

\section{Participants}

A total of 279 children participated in the study. Figure 1 illustrates the progress of subjects through the trial 
Table 1 Children's baseline demographic characteristics as number and percentage (in parentheses) of total and separate research group samples

\begin{tabular}{|c|c|c|c|c|c|c|c|c|}
\hline \multirow{2}{*}{$\begin{array}{l}\text { Characteristics } \\
\text { Sex }\end{array}$} & \multicolumn{2}{|l|}{ Total } & \multicolumn{2}{|c|}{ Intervention (I) } & \multicolumn{2}{|c|}{$\begin{array}{l}\text { Divorced } \\
\text { control (DC) }\end{array}$} & \multicolumn{2}{|c|}{$\begin{array}{l}\text { Non-divorced } \\
\text { control (NDC) }\end{array}$} \\
\hline & & & & & & & & \\
\hline Boy & 150 & $(53.8)$ & 50 & $(48.1)$ & 24 & (64.9) & 76 & $(55.1)$ \\
\hline Girl & 129 & $(46.2)$ & 54 & $(51.9)$ & 13 & $(35.1)$ & 62 & $(44.9)$ \\
\hline Age $M(S D)$ & 7.31 & $(0.81)$ & 7.52 & $(0.94)$ & 7.28 & $(0.92)$ & $7.17 * *$ & (0.63) \\
\hline \multicolumn{9}{|c|}{ Country of birth mother } \\
\hline Netherlands & 217 & $(90.0)$ & 62 & $(82.7)$ & $28^{*}$ & $(100)$ & $127^{*}$ & $(92.0)$ \\
\hline Other & 24 & $(10.0)$ & 13 & $(17.3)$ & 0 & (0) & 11 & (8.0) \\
\hline \multicolumn{9}{|c|}{ Country of birth father } \\
\hline Netherlands & 192 & $(89.7)$ & 55 & $(93.2)$ & 16 & $(94.1)$ & 121 & $(87.7)$ \\
\hline Other & 22 & $(10.3)$ & 4 & $(6.8)$ & 1 & (5.9) & 17 & $(12.3)$ \\
\hline \multicolumn{9}{|c|}{ Education mother } \\
\hline Low & 23 & (8.7) & 13 & $(14.4)$ & 2 & (5.6) & 8 & (5.8) \\
\hline Medium & 96 & $(36.5)$ & 35 & $(38.9)$ & 16 & $(44.4)$ & 45 & $(32.8)$ \\
\hline High & 144 & $(54.8)$ & 42 & $(46.7)$ & 18 & $(50.0)$ & 84 & $(61.3)$ \\
\hline \multicolumn{9}{|c|}{ Education father } \\
\hline Low & 34 & $(13.2)$ & 19 & (21.1) & 4 & (11.1) & 11 & (8.3) \\
\hline Medium & 95 & $(36.8)$ & 31 & (34.4) & 17 & (47.2) & 47 & $(35.6)$ \\
\hline High & 129 & $(50.0)$ & 40 & (44.4) & 15 & (41.7) & $74 *$ & (56.1) \\
\hline
\end{tabular}

One-way ANOVAs with contrast test (I as reference category) and $\chi^{2}$ tests used to evaluate between-group differences

$* p<0.05 ; * * p<0.01$, two-tailed significance
(CONSORT diagram) by group (n): I (104), DC (37) and NDC (138). As indicated in Fig. 1, 108 children initially started the intervention. Four children (3.7\%) did not complete their participation (no reason (2); no transport, swimming class obligations (2)). We report on the remaining 104 children who finished the CODIP-NL intervention and received full intervention dosage. Each child participated in one of nineteen small intervention groups $(M=5.5$ participants, range 3-7 children, modus $=6$ ).

Table 1 summarizes baseline demographic characteristics of the participating children by group, as measured at the pre-test. The sample consisted of 150 boys (53.8\%) and 129 girls $(46.2 \%)$. Their mean age was $7.31(\mathrm{SD}=0.81)$ years at the start of the study. On average, children in the NDC group were 3-4 months younger than children in the I group $(p<0.01)$. The majority $(90.0 \%)$ of children's parents were born in the Netherlands. The proportion of high-educated fathers was higher in the NDC group than in the I and DC groups $(p<0.05)$.

We found no statistically significant differences in divorce-related characteristics between the I and DC groups. The period since divorce or separation, measured by the length of time parents in the I and DC groups had been living separately, varied from 1 month to 8 years $(M=$ 27.7 months, $\mathrm{SD}=22.2$; information available on $n=87$ in I group and $n=32$ in DC group). In most families, parents shared joint custody $(93.1 \%)$ and had agreements in the form of a definite or temporary parenting plan (89.7\%). In respectively 79.8 and $46.6 \%$ of divorced families, there were child support and parent alimony agreements, and for most children, contact arrangements were in place. On a 5 -point scale (higher scores indicating more post-divorce conflict), average conflict scores as reported by mothers were 2.34 and 2.09 in the I and DC groups, respectively. Approximately half of the mothers and fathers had new partners.

\section{Effects of CODIP-NL}

We found significant effects of CODIP-NL on motherreported positive functioning (PEF; see Table 2). Pre- to post-test increases in positive functioning were greater in the I (complete pre- to post-test PEF data available on $n=$ 59) than in the DC ( $n=25$; Cohen's $d=0.97)$ and NDC $(n=93 ; d=1.04)$ groups. In line with this, group leader reports of positive functioning (GLEF) indicated significant increases after participation in CODIP-NL $(t(86)=7.12$; $p<0.001$; see positive functioning in Table 2).

Table 2 also presents effects regarding emotional and behavioral functioning. Mother-reported SDQ scores decreased significantly more in the I (complete pre- to posttest data available on $n=59)$ than in the DC $(n=22)$ and NDC groups $(n=92)$. Effect sizes ranged from a Cohen's $d$ of 0.73 (I vs. DC) and 0.49 (I vs. NDC) for the TDS of 
Table 2 Means and standard deviations (in parentheses) of pre-test, post-test and pre- to post-test between-group differences on primary and secondary outcomes of intervention and control group samples based on available case analyses

\begin{tabular}{|c|c|c|c|c|c|c|c|c|c|c|}
\hline \multirow[b]{2}{*}{ Outcome } & \multirow[b]{2}{*}{ Informant } & \multirow[b]{2}{*}{ Group } & \multicolumn{2}{|l|}{ Pre } & \multicolumn{2}{|c|}{ Post } & \multirow{2}{*}{$\begin{array}{l}\Delta \text { pre-post } \\
M(\mathrm{SD})\end{array}$} & \multicolumn{2}{|c|}{$\begin{array}{l}\text { Difference in } \Delta \text { pre-post } \\
\text { I vs. DC and I vs. NDC }\end{array}$} & \multirow{2}{*}{$\begin{array}{l}\text { Adjusted }^{\mathrm{a}} \\
\text { difference in } \\
\Delta \text { pre-post I vs. DC } \\
\text { and I vs. NDC } \\
M \text { (SD) }\end{array}$} \\
\hline & & & $N$ & $M(\mathrm{SD})$ & $N$ & $M(\mathrm{SD})$ & & $M(\mathrm{SD})$ & $d$ & \\
\hline \multicolumn{11}{|c|}{ Positive functioning } \\
\hline & Mother & I & 73 & $2.27(0.38)$ & 62 & $2.53(0.42)$ & $0.26(0.32)$ & & & \\
\hline & Mother & DC & 28 & $2.57(0.45)$ & 25 & $2.54(0.47)$ & $-0.03(0.26)$ & $-0.29(0.07)^{* * *}$ & 0.97 & $-0.31(0.07)^{* * * *}$ \\
\hline & Mother & NDC & 116 & $2.89(0.37)$ & 94 & $2.83(0.37)$ & $-0.03(0.25)$ & $-0.29(0.05)^{* * *}$ & 1.04 & $-0.32(0.05)^{* * * *}$ \\
\hline & Group leader & I & 102 & $2.92(0.44)$ & 89 & $3.21(0.52)$ & $0.28(0.37)$ & & & \\
\hline \multicolumn{11}{|c|}{ Well-being of child } \\
\hline & Mother & I & 72 & $6.73(1.19)$ & 61 & $7.55(1.01)$ & $0.77(1.02)$ & & & \\
\hline & Mother & DC & 26 & $7.65(1.11)$ & 22 & $7.34(1.30)$ & $-0.15(0.61)$ & $-0.92(0.24)^{* * *}$ & 1.00 & $-0.92(0.25)^{* * *}$ \\
\hline & Mother & NDC & 113 & $8.54(0.97)$ & 92 & $8.47(0.84)$ & $-0.01(0.88)$ & $-0.78(0.15)^{* * *}$ & 0.84 & $-0.74(0.18)^{* * * *}$ \\
\hline & Group leader & I & 102 & $6.53(1.03)$ & 89 & $7.24(1.01)$ & $0.71(0.95)$ & & & \\
\hline \multicolumn{11}{|c|}{$\begin{array}{l}\text { Emotional and } \\
\text { behavioral problems }\end{array}$} \\
\hline \multicolumn{11}{|c|}{ Emotionality } \\
\hline & Mother & I & 72 & $3.69(2.40)$ & 62 & $3.00(2.40)$ & $-0.71(2.19)$ & & & \\
\hline & Mother & DC & 26 & $2.50(1.86)$ & 24 & $2.88(2.44)$ & $0.23(1.82)$ & $0.94(0.46)^{*}$ & 0.45 & $0.86(0.52)$ \\
\hline & Mother & NDC & 113 & $1.80(2.07)$ & 94 & $1.88(1.99)$ & $-0.04(1.55)$ & $0.67(0.31)^{*}$ & 0.37 & $0.47(0.33)$ \\
\hline & Group leader & I & 102 & $2.66(2.36)$ & 89 & $2.28(2.43)$ & $-0.38(2.00)$ & & & \\
\hline \multicolumn{11}{|c|}{ Conduct problems } \\
\hline & Mother & I & 72 & $2.21(1.84)$ & 62 & $1.68(1.51)$ & $-0.56(1.74)$ & & & \\
\hline & Mother & DC & 26 & $1.77(1.84)$ & 24 & $1.96(2.01)$ & $0.09(1.23)$ & $0.65(0.38)$ & 0.41 & $0.77(0.38)^{*}$ \\
\hline & Mother & NDC & 113 & $1.00(1.32)$ & 94 & $1.03(1.38)$ & $-0.01(1.40)$ & $0.55(0.25)^{*}$ & 0.36 & $0.49(0.27)$ \\
\hline & Group leader & I & 102 & $0.82(1.14)$ & 89 & $0.83(1.39)$ & $-0.01(1.02)$ & & & \\
\hline \multicolumn{11}{|c|}{ Hyperactivity } \\
\hline & Mother & I & 72 & $4.53(2.85)$ & 62 & $3.76(3.01)$ & $-0.47(2.03)$ & & & \\
\hline & Mother & DC & 26 & $3.65(2.68)$ & 24 & $4.25(2.64)$ & $0.50(2.02)$ & $0.97(0.46)^{*}$ & 0.49 & $1.21(0.50)^{*}$ \\
\hline & Mother & NDC & 113 & $3.25(2.72)$ & 94 & $3.47(2.83)$ & $0.11(1.70)$ & $0.58(0.31)$ & 0.32 & $0.65(0.33)$ \\
\hline & Group leader & I & 102 & $3.95(2.96)$ & 89 & $3.64(3.18)$ & $-0.40(2.23)$ & & & \\
\hline \multicolumn{11}{|c|}{ Peer problems } \\
\hline & Mother & I & 72 & $1.85(1.77)$ & 62 & $1.29(1.41)$ & $-0.27(1.34)$ & & & \\
\hline & Mother & DC & 26 & $1.58(1.96)$ & 24 & $1.96(2.35)$ & $0.36(1.43)$ & $0.63(0.35)$ & 0.47 & $0.81(0.36)^{*}$ \\
\hline & Mother & NDC & 113 & $0.81(1.25)$ & 94 & $0.87(1.34)$ & $0.02(1.45)$ & $0.29(0.24)$ & 0.21 & $0.42(0.27)$ \\
\hline & Group leader & I & 102 & $1.98(1.80)$ & 89 & $1.58(1.80)$ & $-0.33(1.78)$ & & & \\
\hline \multicolumn{11}{|c|}{ Prosocial behavior } \\
\hline & Mother & I & 72 & $7.97(1.75)$ & 62 & $8.24(1.70)$ & $0.19(1.71)$ & & & \\
\hline & Mother & DC & 26 & $8.08(1.32)$ & 24 & $7.83(1.88)$ & $-0.18(1.62)$ & $-0.37(0.41)$ & 0.22 & $-0.33(0.44)$ \\
\hline & Mother & NDC & 113 & $8.27(1.62)$ & 94 & $8.04(1.79)$ & $-0.05(1.59)$ & $-0.24(0.27)$ & 0.15 & $-0.37(0.30)$ \\
\hline & Group leader & I & 102 & $6.64(2.95)$ & 89 & $7.90(2.50)$ & $1.07(3.00)$ & & & \\
\hline \multicolumn{11}{|c|}{ Total difficulties (TDS) } \\
\hline & Mother & I & 72 & $12.28(6.39)$ & 62 & $9.73(5.54)$ & $-2.02(4.55)$ & & & \\
\hline & Mother & DC & 26 & $9.50(6.41)$ & 24 & $11.04(7.26)$ & $1.18(4.06)$ & $3.20(1.07)^{* *}$ & 0.73 & $3.66(1.01)^{* * *}$ \\
\hline & Mother & NDC & 113 & $6.85(5.32)$ & 94 & $7.26(5.30)$ & 0.08 & $2.09(0.71)^{* *}$ & 0.49 & $2.03(0.76)^{* *}$ \\
\hline & Group leader & I & 102 & $9.41(5.66)$ & 89 & $8.34(6.39)$ & $-1.13(4.39)$ & & & \\
\hline
\end{tabular}

Statistical significance of contrast $t$-tests comparing pre- to post-test differences ( $\Delta$ pre-post) between the intervention (I) and control groups (DC: divorced control; NDC: non-divorced control) are marked in this table in the I vs. DC and I vs. NDC column

$* p<0.05 ; * * p<0.01 ; * * * p<0.001$, two-tailed significance

${ }^{a}$ Adjusted for country of birth of the mother (i.e., children with mothers born in the Netherlands), age of the child, and education of the father

children in the CODIP-NL group (I) compared with children in the two comparison groups (DC and NDC), to $d=$ 0.45 (I vs. DC) and $d=0.37$ (I vs. NDC) for emotional problems, $d=0.36$ for conduct problems (I vs. NDC), and $d=0.49$ for hyperactivity (I vs. DC). However, after adjustment for country of birth of the mother (i.e., as all mothers in the DC group were born in the Netherlands, we restricted to all children with mothers born in the 
Netherlands), age of the child and education of the father, emotional and conduct problems (I vs. NDC) did not remain significant. Instead, adjusted differences in pre- to post-test conduct problems and peer problems between the I and DC groups were significant (see Table 2). Group leader-reported SDQ-TDS decreased after participation $(t(86)=-2.40$, $p=0.02$ ), and prosocial behavior of participating children was higher at the post-test than at the pre-test $(t(86)=3.32, p=0.001)$.

Regarding secondary outcomes, mother-reported child well-being increased more in the I group (complete pre- to post-test data available on $n=57)$ than in the DC $(n=20$; $d=1.00)$ and in the NDC groups $(n=90 ; d=0.84)$ (see Table 2). Group leader-reported child well-being also increased $(t(86)=6.96, p<0.001)$ after participation in CODIP-NL.

\section{Discussion}

In a quasi-experimental study, we assessed the impact of 12 weekly sessions of the preventive group intervention CODIP-NL for 6- to 8-year-old children with divorced parents. In accordance with our hypotheses, we found enhanced child positive functioning, fewer emotional and behavioral problems, and increased emotional well-being of participating children. The effects were robust across outcomes, sized medium to large on all outcomes. These findings are consistent with those in the pre-experimental pilot study in the Netherlands (Klein Velderman et al., 2018) and confirm findings on effects of CODIP in the US setting (e.g., Alpert-Gillis et al., 1989; Pedro-Carroll et al., 1999).

Based on intervention aims and key elements, the positive changes after participation in CODIP-NL may be due to four possible mechanisms: (1) emotional support; (2) increased awareness of own feelings and regulation of emotion, accurate understanding of and possibly hope regarding divorce, and reduced feelings of guilt; (3) better problem-solving skills; and (4) greater self-confidence. Regarding social support, the intervention leads to interaction with peers who have also experienced parental divorce. This may particularly help to reduce children's sense of isolation and loneliness and promote a sense of companionship and confidence (Pedro-Carroll \& Alpert-Gillis, 1997). Previous work has indicated that after CODIP-NL (2011) $70 \%$ of the children felt less lonely, and $80 \%$ indicated that they had made new friends. This support of social interaction may thereby have contributed specifically to increases in the well-being of the participating children, as found in this study.

A second working mechanism of CODIP-NL may be that it reduces misconceptions about divorce which are common among young children (e.g., Pedro-Carroll, 2010). Discussing these feelings and reducing misconceptions and unrealistic thoughts is, therefore, an important goal of CODIP-NL. To do so, techniques similar to psychoeducation and cognitive behavioral therapy's cognitive restructuring are applied, for example by discussing faces with different emotions.

Third, working on better problem-solving skills has in several interventions been shown to be effective in preventing problems after divorce (Malouff et al., 2007; Sandler et al., 1994, 2000; Wolchik et al., 2000). Instead of teaching the children what to think, CODIP-NL teaches them how to think when experiencing challenging situations. This may contribute to more resilience and positive functioning, and fewer emotional and behavioral problems in the sometimes challenging daily lives of CODIP-NL participants. We expect that, when children learn to think in terms of alternative solutions and anticipate the consequences of their behaviors, they are better able to cope with everyday problems.

Fourth and finally, CODIP-NL works on children's selfperception, e.g., by assigning them to work on their "I am special booklet" (a kind of ego document consisting of separate worksheets). The booklet helps children to identify their positive characteristics. In addition, children receive compliments and are positively reinforced during the group sessions. Children's self-perception is found to be related to, among other things, their functioning in school, socialemotional functioning, well-being, and coping (O'Mara et al., 2006).

This study has a number of strengths, specifically its quasi-experimental design with use of two control groups, and its embedding in routine care. In order to reduce the potential effects of possible sampling bias due to non-randomization, we used a pre-post-test design. Moreover, analyses with adjustment for differences in the background in the composition of the groups yielded very similar results. However, this study also has some limitations, in particular the relatively high dropout in the two comparison groups. Second, the use of a quasi-experimental design may have affected the comparability of the three groups. We cannot fully exclude a possible resulting bias. Third, mothers and group leaders were not blind to children's participation in CODIP-NL, which may have led to some overestimation of effects. Fourth, the Cronbach's alpha of the SDQ-TDS-score as reported by group leaders appeared to be relatively low (i.e., alpha $=0.55$ ). This may be because this measure was too complex for them, as they had only a limited overview of these children's psychosocial problems. Findings regarding this should thus be considered with caution.

Moreover, we did not reach the anticipated sample size of 52 in all groups (i.e., not in DC), somewhat reducing the power of our study, but sufficient to detect medium to large effects on the primary and secondary outcomes. Post hoc 
power analysis showed that a Cohen's $d$ effect size of 0.67 could be detected with samples sizes of 59 and 26 (twosided alpha $=0.05$, power $=80 \%$ ). Finally, we adjusted for multiple testing with a cut-off for statistical significance was set at 0.01 (noted as $* *$ in Table 2) (i.e., 0.05/8 0.01, because of our use of eight outcomes and the related Bonferroni correction). This is a conservative method for adjusting for multiple testing.

\section{Conclusion}

CODIP-NL is a promising intervention to effectively enhance the positive functioning and emotional well-being of participating children, as well as reduce their emotional and behavioral problems. This supports a broader application of CODIP to support children's positive functioning and well-being and decrease emotional and behavioral problems after their parents' divorce. These promising findings deserve replication in a larger scaled randomized trial, as well as with other age groups and in other countries.

Acknowledgements This research was supported by a grant from a major Dutch non-profit funding body, ZonMw (the Netherlands Organization for Health Research and Development: Grant No. 531005009). The authors were independent of the funders and the funders had no role in the project. CODIP-NL received scientific validation in a Dutch database by the Dutch Youth Institute. The first pilot study into CODIP-NL received the national ZonMw "Pearl Award" for strong innovative power (March 2013). We gratefully acknowledge Dr Pedro-Carroll and Wendy van Vliet for their contribution to the development of the current version of CODIP-NL, as well as group leaders for leading the CODIP-NL groups in this study. We thank L. van Harten, MSc, group leaders, and parents for their contribution to data collection.

\section{Compliance with Ethical Standards}

Conflict of Interest This manuscript has not been and will not be published in this or a similar form (in print or electronically, including on a website) and is neither accepted for publication elsewhere nor under consideration by another journal. This research was supported by a grant from ZonMw (Grant No. 531005009). The authors were independent of the funders and the funders had no role in the project. The authors do not have any conflict of interest and all have contributed significantly to the manuscript. All authors have confirmed that they have read and approved the final version of the paper and that they believe that the paper represents honest work. They are able to verify the validity of the results reported.

Publisher's note Springer Nature remains neutral with regard to jurisdictional claims in published maps and institutional affiliations.

Open Access This article is licensed under a Creative Commons Attribution 4.0 International License, which permits use, sharing, adaptation, distribution and reproduction in any medium or format, as long as you give appropriate credit to the original author(s) and the source, provide a link to the Creative Commons license, and indicate if changes were made. The images or other third party material in this article are included in the article's Creative Commons license, unless indicated otherwise in a credit line to the material. If material is not included in the article's Creative Commons license and your intended use is not permitted by statutory regulation or exceeds the permitted use, you will need to obtain permission directly from the copyright holder. To view a copy of this license, visit http://creativecommons. org/licenses/by/4.0/.

\section{References}

Alpert-Gillis, L. J., Pedro-Carroll, J. L., \& Cowen, E. L. (1989). The children of divorce intervention program: Development, implementation, and evaluation of a program for young urban children. Journal of Consulting and Clinical Psychology, 57, 583-589. https://doi.org/10.1037/0022-006X.57.5.583.

Amato, P. R. (2001). Children of divorce in the 1990s: An update of the Amato and Keith (1991) meta-analysis. Journal of Family Psychology, 15, 355-370. https://doi.org/10.1037/0893-3200.15.3.355.

Amato, P. R., \& James, S. (2010). Divorce in Europe and the United States: Commonalities and differences across nations. Family Science, 1, 2-13. https://doi.org/10.1080/19424620903381583.

Benardi, F., \& Radl, J. (2014). The long-term consequences of parental divorce for children's educational attainment. Demographic Research, 30, 1653-1680. https://doi.org/10.4054/DemRes.2014. 30.61 .

Boertien, D. (2020). The conceptual and empirical challenges of estimating trends in union stability: Have unions become more stable in Britain? In D. Mortelmans (Ed.), Divorce in Europe: New insights in trends, causes and consequences of relation break-ups (eBook). European Studies of Population, 21 (pp. 17-36) Cham, Switzerland: Springer Open. https://doi.org/10. 1007/978-3-030-25838-2.

Bohman, H., Låftman, S. B., Päären, A., \& Jonsson, U. (2017). Parental separation in childhood as a risk factor for depression in adulthood: A community-based study of adolescents screened for depression and followed up after 15 years. BMC Psychiatry, 17, 117 https://doi.org/10.1186/s12888-017-1252-z.

Cantril, H. (1965). The pattern of human concerns. New Brunswick, NJ: Rutger University Press.

Carr, C. M., \& Wolchik, S. A. (2015). Marital status, divorce, and child development. In J. D. Wright (Ed.), International encyclopedia of the social \& behavioral sciences (2nd ed., pp. 518-524). Elsevier. https://doi.org/10.1016/B978-0-08-097086-8.23222-4.

CDC (2020). National marriage and divorce rate trends. Retrieved November 6, 2020, from: https://www.cdc.gov/nchs/data/dvs/na tional-marriage-divorce-rates-00-18.pdf.

Dissing, A. S., Dich, N., Nybo Andersen, A. M., Lund, R., \& Rod, N. H. (2017). Parental break-ups and stress: Roles of age \& family structure in 44509 pre-adolescent children. The European Journal of Public Health, 27, 829-834. https://doi.org/10.1093/ eurpub/ckx040.

Eurostat (2020). Marriage and divorce statistics. Statistics Explained. Retrieved November 6, 2020, from: https://ec.europa.eu/eurostat/ statistics-explained/index.php/Marriage_and_divorce_sta tistics\#Fewer_marriages.2C_more_divorces.

Goodman, R. (1997). The strengths and difficulties questionnaire: A research note. Journal of Child Psychology and Psychiatry, 38, 581-586. https://doi.org/10.1111/j.1469-7610.1997.tb01545.x.

Grych, J. H., Seid, M., \& Fincham, F. D. (1992). Assessing marital conflict from the child's perspective: The children's perception of interparental conflict scale. Child Development, 63, 558-572. https://doi.org/10.2307/1131346.

Klein Velderman, M., \& Pannebakker, F. D. (2019). Databank effectieve jeugdinterventies: Beschrijving 'Dappere Dino's' 
[Registry of effective youth interventions: Description 'Courageous Dinosaurs']. Utrecht: Nederlands Jeugdinstituut. https://www.nji.nl/nl/Download-NJi/Werkblad/Uitgebreidebeschrijving-Dappere-Dino-s-(CODIP-NL-6-8-jaar).pdf.

Klein Velderman, M., Pannebakker, F. D., Van Vliet, W., \& Reijneveld, S. A. (2018). Prevention of divorce-related problems in Dutch 4- to 8-year-olds: Cultural adaptation and pilot study of the Children of Divorce Intervention Program. Research on Social Work Practice, 28, 415-427. https://doi.org/10.1177/1049731516644504.

Lemmers, O., Cook, J., Detiger, M., \& Van der Houwen, K. (2019). Scheidingen - en de kinderen dan? 2015-2017 [Union dissolutions - and what about the children? 2015-2017]. The Hague: CBS. https://www.cbs.nl/nl-nl-/maatwerk/2019/24/beeindigderelaties-en-minderjarige-kinderen-2015-2017.

Malouff, J. M., Thorsteinsson, E. B., \& Schutte, N. S. (2007). The efficacy of problem solving therapy in reducing mental and physical health problems: A meta-analysis. Clinical Psychology Review, 27, 46-57. https://doi.org/10.1016/j.cpr.2005.12.005.

Office for National Statistics (2015). Dataset: Divorces in England and Wales, children of divorced couples: historical data. 2013. Retrieved October 17, 2019, from https://www.ons.gov.uk/ peoplepopulationandcommunity/birthsdeathsandmarriages/divorce/ datasets/divorcesinenglandandwaleschildrenofdivorcedcouples.

O'Mara, A. J., Marsh, H. W., Craven, R. G., \& Debus, R. L. (2006). Do self-concept interventions make a difference? A synergistic blend of construct validation and meta-analysis. Educational Psychologist, 41, 181-206. https://doi.org/10.1207/s15326985ep4103_4.

Pedro-Carroll, J. L. (2005). Fostering resilience in the aftermath of divorce: The role of evidence based programs for children. Family Court Review, Special Issue on Prevention, 52-64. https://doi.org/10.1111/j.1744-1617.2005.00007.x.

Pedro-Carroll, J. L. (2010). Putting children first: Proven parenting strategies for helping children thrive through divorce. New York, NY: Avery (Penguin).

Pedro-Carroll, J. L., \& Alpert-Gillis, L. J. (1997). Preventive interventions for children of divorce: A developmental model for 5 and 6 year old children. The Journal of Primary Prevention, 18, 5-23. https://doi.org/10.1023/A:1024601421020.

Pedro-Carroll, J. L., \& Cowen, E. L. (1985). The children of divorce intervention project: An investigation of the efficacy of a schoolbased prevention program. Journal of Consulting and Clinical
Psychology, 53, 603-611. https://doi.org/10.1037/0022-006x.53. 5.603.

Pedro-Carroll, J., \& Klein Velderman, M. (2015). Extending the global reach of a play-based intervention for children dealing with separation and divorce. In L. A. Reddy, T. M. Files-Hall, \& C. Schaefer (Eds.), Empirically-based play interventions for children (2nd ed., pp. 35-53). Washington, DC: American Psychological Association.

Pedro-Carroll, J. L., Sutton, S. E., \& Wyman, P. A. (1999). A two-year follow-up evaluation of a preventive intervention for young children of divorce. School Psychology Review, 28, 467-476. https://doi.org/10.1080/02796015.1999.12085978.

Research and Documentation Centre - WODC (2019). Scheidingen 2018: Gerechtelijke procedures en gesubsidieerde rechtsbijstand [Divorces 2018: Legal proceedings and subsidized legal aid]. Factsheet 2019-1. The Hague: WODC.

Sandler, I. N., Tein, J. Y., Mehta, P., Wolchik, S., \& Ayers, T. (2000). Coping efficacy and psychological problems of children of divorce. Child Development, 71, 1099-1118. https://doi.org/10. 1111/1467-8624.00212.

Sandler, I. N., Tein, J. Y., \& West, S. G. (1994). Coping, stress, and the psychological symptoms of children of divorce - A crosssectional and longitudinal-study. Child Development, 65, 1744-1763. https://doi.org/10.2307/1131291.

Spruijt, E., \& Duindam, V. (2010). Joint physical custody in the Netherlands and the well-being of children. Journal of Divorce \& Remarriage, 51, 65-82. https://doi.org/10.1080/10502550903423362.

Van Dijk, R., Van der Valk, I., Dekovic, M., \& Branje, S. (2020). Meta-analysis on interparental conflict, parenting, and adjustment in divorced families: Examining mediation using meta-analytic structural equation models. Clinical Psychology Review, 79, 101861. https://doi.org/10.1016/j.cpr.2020.101861.

Weaver, J. M., \& Schofield, T. J. (2015). Mediation and moderation of divorce effects on children's behavior problems. Journal of Family Psychology, 29, 39-48. https://doi.org/10.1037/fa m0000043.

Wolchik, S. A., West, S. G., Sandler, I. N., Tein, J. Y., Coatsworth, D., \& Lengua, L., et al. (2000). An experimental evaluation of theory-based mother and mother-child programs for children of divorce. Journal of Consulting and Clinical Psychology, 68, 843-856. https://doi.org/10.1037/0022-006X.68.5.843. 